\title{
Freeze the pain away: The role of cryoanalgesia during a Nuss procedure
}

\author{
Manu Sancheti, MD
}

\author{
From the Division of Cardiothoracic Surgery, Emory University School of Medicine, Atlanta, Ga. \\ Disclosures: Author has nothing to disclose with regard to commercial support. \\ Received for publication Nov 2, 2015; accepted for publication Nov 2, 2015; available ahead of print Dec 6, 2015. \\ Address for reprints: Manu Sancheti, MD, 5569 Peachtree Dunwoody Rd, Suite 200, Atlanta, GA 30342 (E-mail: \\ msanch2@emory.edu). \\ J Thorac Cardiovasc Surg 2016;151:889-90 \\ $0022-5223 / \$ 36.00$ \\ Copyright (C) 2016 by The American Association for Thoracic Surgery \\ http://dx.doi.org/10.1016/j.jtcvs.2015.11.001
}

In this issue of the Journal, Kim and colleagues ${ }^{1}$ describe a surgical technique in which they provide a unique approach to postoperative pain control after a Nuss procedure for pectus excavatum. Their group describes a novel thoracoscopic transthoracic approach for the application of cryoanalgesia to the contralateral intercostal nerves. According to their single patient experience, this technique allowed the use of a minimally invasive method to apply the cryoprobe accurately to the associated intercostal nerves while avoiding the anatomic obstacles often present in thoracoscopy because of the rigidity of the chest wall.

Thoracic surgery, whether approached through minimally invasive methods or thoracotomy, is a painful art. The extensive neural network along the parietal pleura and the constant motion of the chest wall with respiration can lead to significant discomfort for thoracic surgical patients. This is especially true of those patients who undergo chest wall reconstructions, such as a Nuss procedure. Because of thoracic procedures' effects on respiratory mechanics and pulmonary toilet, the importance of satisfactory postoperative analgesia in the thoracic surgical patient population cannot be overstated.

The most effective postoperative analgesic method in thoracic surgery has long been debated and continues to be questioned. Options include patient-controlled narcotic analgesia, thoracic epidural placement, paravertebral block, direct intercostal nerve block, and, historically, cryoanalgesia. ${ }^{2}$ Current clinical practice uses a multifaceted approach with the combination of an intercostal nerve block supplemented with narcotic or nonsteroidal antiinflammatory medications.

Even with a thoracoscopic approach, the pain from a Nuss procedure is thought to be quite significant and prolonged, likely as a result of the stresses on the reconstructed anterior chest wall. ${ }^{3}$ An ideal pain management technique for this procedure should therefore be robust and long lasting. The most common technique for postoperative analgesia currently used after the Nuss procedure is thoracic epidural analgesia with supplemental narcotics. ${ }^{4}$ Several

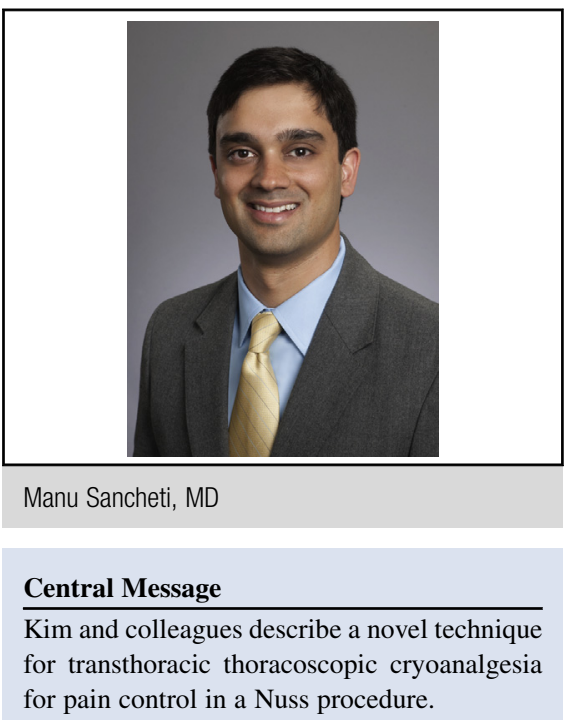

See Article page 887.

small series have described additional methods, such as paravertebral block, intercostal nerve block, high-dose antiinflammatory medication, and scoring of the deformed cartilage cartridges. ${ }^{3,5,6}$ No true consensus has been reached regarding the best method, however, and in most cases a multi-faceted approach with supplemental long-term narcotics is clinically used.

Kim and colleagues ${ }^{1}$ chose to study the utility of cryoanalgesia for postoperative pain control in the patient who has undergone a Nuss procedure. Cryoanalgesia uses the concept of myelin sheath and nerve conduction disruption with extreme cold temperatures. Nerve functional recovery takes about 1 to 3 months and thus theoretically provides long-term analgesia. ${ }^{2}$ Studies analyzing the benefit of cryoanalgesia in the thoracoscopic surgical population is quite sparse. Several studies, however, have evaluated cryoanalgesia in patients who have undergone thoracotomy. Most studies reported no clear benefit of cryoanalgesia relative to narcotics alone when examining pain relief and respiratory mechanics. When compared with thoracic epidural, cryoanalgesia provided worse pain relief and need for increased supplemental narcotics. Additionally, cryoanalgesia carries a $20 \%$ to $30 \%$ long-term neuralgia rate. ${ }^{2}$

Although the utility of cryoanalgesia in the thoracic surgical patient population has not been well proven, Kim and colleagues ${ }^{1}$ should be congratulated on a unique 
approach to its role in the patient who underwent a Nuss procedure through a thoracoscopic approach. As described in the article, the curvature and rigidity of the chest wall make the application of the cryoprobe to the ipsilateral posterior intercostal nerve difficult. Kim and colleagues ${ }^{1}$ designed a novel method by which the cryoprobe approaches the contralateral nerves through a transthoracic route traversing the anterior mediastinum. In contrast, the main weakness of this article encompasses the question regarding the unproven utility of cryoanalgesia for postoperative analgesia in the thoracic surgical patient. Despite the imaginative surgical technique, should we be performing this procedure on patients on the basis of a single patient experience and no historically proven clinical effectiveness? For now, it is the role of the thoracic surgeon to continue to be inventive and judicious in providing the best means of postoperative comfort for our patients by using a multifaceted approach of proven techniques.

\section{References}

1. Kim S, Idowu O, Palmer B, Lee SH. Use of transthoracic cryoanalgesia during a Nuss procedure. J Thorac Cardiovasc Surg. 2016;151:887-8.

2. Detterbeck FC. Efficacy of methods of intercostal nerve blockade for pain relief after thoracotomy. Ann Thorac Surg. 2005;80:1550-9.

3. Nagasao T, Hamamoto Y, Tamai M, Kogure T, Jiang H, Takano N, et al. Scoring of deformed costal cartilages reduces postoperative pain after Nuss procedure for pectus excavatum. Thorac Cardiovasc Surg. 2016;64:62-9.

4. Muhly WT, Maxwell LG, Cravero JP. Pain management following the Nuss procedure: a survey of practice and review. Acta Anaesthesiol Scand. 2014;58:1134-9.

5. Yang W, Ming YC, Kau YC, Liao CC, Tsai SC, Wong KM, et al. A comparison of parecoxib and thoracic epidural anesthesia for postoperative analgesia following Nuss procedure. J Pediatr Surg. August 28, 2015 [Epub ahead of print].

6. Hall Burton DM, Boretsky KR. A comparison of paravertebral nerve block catheters and thoracic epidural catheters for postoperative analgesia following the Nuss procedure for pectus excavatum repair. Paediatr Anaesth. 2014;24:516-20. 